\title{
Does the patients age at cancer diagnosis affect microvessels density in uterine sarcoma tissues?
}

\author{
Marcin Bobiński, Wiesława Bednarek, Karolina Okła, Grzegorz Polak, \\ Małgorzata Sobstyl, Iwona Wertel, Jan Kotarski \\ $1^{\text {st }}$ Chair and Department of Gynecological Oncology and Gynecology, Medical University of Lublin, Poland
}

\begin{abstract}
Objectives: The objective of the study was to retrospectively evaluate the density of vessels exhibiting positive glycoprotein CD34 expression in the uterine leiomyosarcoma tissues and their correlation with the age of patients at the time of tumor diagnosis.

Material and methods: The archival paraffin blocks with the cancer tissues collected from 50 patients suffering from uterine leiomyosarcoma were used together with their clinical and demographic data. The immunohistochemical peroxidase-dependent methods were used to detect microvessels with positive CD34 expression. The glycoprotein CD34 expression was evaluated as a density of microvessel showing the positive immunohistochemical reaction ( $\left.M V D_{C D 34}\right)$.

Results: The negative, statistically significant correlation between the age of patients (at the moment diagnosis) and the MVDCD34+ ( $R=-0.289, p=0.042)$ was found.

Conclusions: The study's findings may suggest that the tissues of younger people constitute a permissive environment for pro-angiogenic factors.
\end{abstract}

Key words: microvessels density, uterine sarcoma, patient age

\section{INTRODUCTION}

The components necessary for the proper functioning of cells are able to diffuse only to a very limited area around blood vessels, therefore, it is necessary virtually in all tissues of the body to have a suitably dense network of vessels. The cells with high metabolism such as cancer cells, require continuous supply of reactants and the discharge of metabolic products for their development. Therefore, the formation of new blood vessels is necessary for the development of tumors [1].

The process of angiogenesis is a subject of complex regulation, and its intensity depends on the established balance between pro-angiogenic and anti-angiogenic factors. Many substances influencing this process have been described, but the complexity of the relationships between them, their effect on the density of each of the cell surface receptors involved in angiogenesis and the expression of their genetic material, make the process of angiogenesis still not fully explored. It should be noted that the formation of tumor vessels to some degree is a subject to systemic regulation as well as to the influence of the tumor itself, therefore all-encompassing knowledge of this problem is particularly difficult to obtain.

While discussing the process of tumor angiogenesis, it is worth to note that the formed vessels do not often have the proper structure and are characterized by abnormal space structure, (tumor cells build into their walls). Moreover, the cells building these vessels (endothelial cells, pericytes) often do not fully develop a phenotype characteristic of these cells in normal vessels. Taking into account the fact that one of the major factors activating the process of tumor angiogenesis is hypoxia, abnormal structure and thus the function of tumor blood vessels leads to a secondary activation of pro-angiogenic factors, which in turn induces 
a chaotic vasculature formation and transient ischemia within tumors [3].

Uterine sarcomas are relatively rare uterine tumors of mesenchymal origin. The biology of sarcomas differs considerably from the much better-known biology of tumors of epithelial origin. This fact seems to be responsible for the limited efficacy of the cancer therapeutic methods in this group which have proven effective in other cancers.

The CD34 (the alternative names: HPCA1, gp105-120) is a transmembrane glycoprotein of a molecular weight of $67 \mathrm{kDa}$, occurring e.g. on endothelial cells. Apart from the endothelium, it occurs physiologically on the surface of hematopoietic cells, stem cells, osteoclasts, the precursor cells of B and T lymphocytes. Moreover, CD34+ was also found in some cancers such as lymphoblastic leukemia, gastrointestinal stromal tumors (GIST), Kaposi's sarcoma, vascular tumors [4]. The role of glycoprotein CD34 is not fully understood, it is believed, however, that it plays a role in the process of adhesion and cell migration.

The presence of the CD34 glycoprotein on the surface of endothelial cells allows its use as a marker for the presence of these cells in tissues and thereby an assessment the vascularity of the examined tissues $[2,5]$. Currently, besides such proteins as CD105, CD31, vWF, VII factor is one of the most frequently used markers in the assessment of blood vessel density. Many studies have demonstrated its high sensitivity and specificity in the evaluation of microvessel density (MVD). Apart from the CD34+ vessel density, the microvessel area parameter (MVA) is used as the percentage of the area of the CD34+ cells in the visual field. In the studies carried out in renal cancer, the superiority of vessels density evaluation with the use of CD34 in comparison to CD31 was found. Moreover, the correlation between $\mathrm{MVD}_{\mathrm{CD} 34+}$, the histological type of tumor and the time of the overall survival of patients was shown. The evaluation of MVD with the use of antibodies targeted against glycoprotein CD34 is possible in the light microscope and due to the numerous studies conducted in this way, the obtained results can be compared. It is significant from the point of view of results comparability that $\mathrm{MVD}_{\mathrm{CD} 34+}$ is defined as an absolute value, i.e. the number of vessels showing the color reaction in $\mathrm{mm}^{2}$ [6].

\section{OBJECTIVES}

The aim of the study is to retrospectively evaluate the density of vessels exhibiting positive glycoprotein CD34 expression in the uterine leiomyosarcoma tissues and their correlation with the age of patients at the time of tumor diagnosis.

\section{MATERIAL AND METHODS}

The study group comprised of 50 patients with the diagnosis of the uterine leiomyosarcoma who were operated in the $1^{\text {st }}$ Chair and Department of Gynecological Oncology and Gynecology of the Medical University of Lublin in 2000-2013. The histology of all of cases was leiomyosarcoma, slides were assessed by two independent, well experienced pathologists who confirmed primary diagnosis. 33 (66\%) patients enrolled to the study were on FIGO I stage, 6 (12\%), 5 (10\%), 6 (12\%) patients were on FIGO II, III and IV respectively.

In the studies, the archival paraffin blocks with the cancer tissues were used together with the clinical and demographic data of patients. The immunohistochemical peroxidase-dependent methods were used. The primary antibody Monoclonal Mouse anti human CD34 Class II Clone QBEnd10 was used as marker together with the secondary antibody Dako EnVision+System- HRPLabelled Polymer Anti Mouse. The staining was conducted according to the guidance of antibodies' manufacturer. Positive control was performed by obtaining color reaction with primary antibody against CD34 in the tissue of human tonsil (according to recommendations of manufacturer). Negative control was performed by applying the protocol without primary antibody in LMS tissue.

The glycoprotein CD34 expression was evaluated as a density of microvessel showing the positive immunohistochemical reaction $\left(\mathrm{MVD}_{\mathrm{CD} 34}\right)$. The evaluation was made with the use of the light microscope at $200 \times$ magnification in ten fields of view (hot spot), which corresponds to the microvessel density in the area of $20 \times 0.7850 \mathrm{~mm}^{2}=15.7 \mathrm{~mm}^{2}$.

The correlations between variables were evaluated with the Spearman's test.

\section{RESULTS}

The patients average age was 52.84 (median 51.50, SD 12.36, min. 29 years old, max. 76 years old). For purposes of statistical analysis patients were divided into 3 groups depending on their age at cancer diagnosis. Group I - under 50 years old (21 patients), group II $-50-70$ years old (21 patients), group III - over 70 years old (8 patients).

In all studied tumors, the presence of CD34+ vessels was found. While analyzing the correlation between the examined variables, the negative, statistically significant correlation between the age of patients (at the moment of diagnosis) and the $\mathrm{CD} 34+$ microvessel density $\left(\mathrm{MVD}_{\mathrm{CD} 34+}\right)$ : $R=-0.289, p=0.042$ was found (Fig. 1). No significant correlation was found between stage of clinical advancement (according to FIGO) and MVD $\mathrm{CD} 34+$.

\section{DISCUSSION}

While discussing the obtained results of correlation between CD34+ vessel density and the age of patients at the moment of diagnosis, the negative, statistically significant correlation is crucial. In most available comparative studies, the authors scheduling the selection of groups tend to yield a maximum of similarity with respect to demo- 


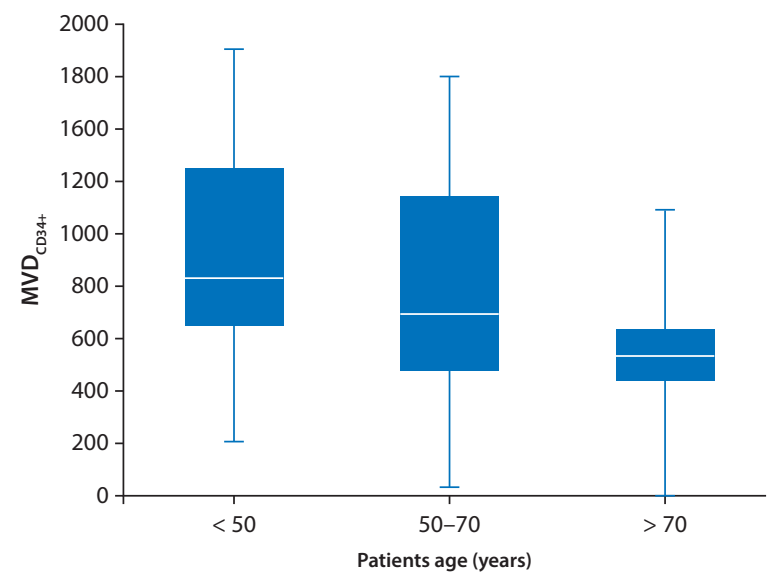

Figure 1. CD34+ microvessels density and patients age in uterine sarcoma (presented as median (white, horizontal line), 25 percentile (lower quartile), 75 percentile (upper quartile) and outliers)

graphic features, therefore such observations are rarely presented in reports. From this point of view, the results of some basic research appear to be interesting. Reed et al. reported significantly lower vessel density in cell cultures of malignant melanoma and prostate carcinoma implanted subcutaneously in older than younger mice [7]. Moreover, Sadoun et al. showed significant, age-dependant differences in expression of TGF-beta1, VEGF and TSP-2 within the implanted tumors [8].

The negative correlation between the age of patients with osteosarcoma and the vessel density within the tumor was also observed by Kubo et al. [9]. The results of the described studies seem to suggest that the tissues in younger people constitute a permissive environment for pro-angiogenic factors. Therefore, the perspective of the expression evaluation of the extracellular factors regulating angiogenesis such as metalloproteinases, cyclooxygenase, or nitric oxide synthase in uterine sarcoma and their correlation with the age of patients seem to be interesting. Such observations could contribute to works on the introduction of individualized therapy of these tumors. It may in fact turn out that some substances currently used in experimental cancer therapy may have a particular activity in selected patients, e.g. in younger patients or in cases of tumors presenting overexpression of selected pro-angiogenic factors. Taking into account the potential role of extracellular factors that activate the process of angiogenesis, some hopes are drawn to the metalloproteinase inhibitors implementation. The evaluation of the metalloproteinases and their inhibitors activity in LMS together with the results concerning the vessel density have a chance to complete substantially the understanding of the mechanisms that ensure perfusion in tumors. It should also be noticed that the results obtained in this way could contribute to planning the experimental research with the use of new, targeted therapies. Starting from the well documented assumption that the tumor growth is dependent on the development of the vasculature, showing the correlation between the age of patients and the vessel density in tumors that were diagnosed can, in some way, correspond to the differences observed in some cancers concerning the dynamics of tumor growth depending on the age of a patient. Such kind of studies were conducted in breast or thyroid cancer [10-12].

\section{CONCLUSIONS}

The statistically significant, negative correlation was found between the CD34+ vessel density and the age of patients at the moment of a diagnosis. It might suggest that the tissues of younger people constitute a permissive environment for pro-angiogenic factors.

\section{REFERENCES}

1. Wang Y, Yao X, Ge J, et al. Can vascular endothelial growth factor and microvessel density be used as prognostic biomarkers for colorectal cancer? A systematic review and meta-analysis. ScientificWorldJournal. 2014: 102736, doi: 10.1155/2014/102736, indexed in Pubmed: 25143961.

2. Sacewicz I, Wiktorska M, Wysocki T, et al. Mechanisms of cancer angiogenesis. Postepy Hig Med Dosw. 2009; 14(63): 159-168.

3. Szala S, Jarosz M. Nowotworowe naczynia krwionośne. Postępy Higieny i Medycyny Doświadczalnej. 2011; 65: 437-446, doi: 10.5604/ /17322693.951193.

4. Holyoake TL, Alcorn MJ, Franklin IM. The CD34 antigen: potential clinical advantages of CD34 selection. Clin Oncol (R Coll Radiol). 1996; 8(4): 214-221, indexed in Pubmed: 8870998.

5. Czekierdowski A, Czekierdowska S, Daniłoś J. Ocena roli badania zjawiska "mimikry naczyniowej” i gęstości mikronaczyń w nowotworach złośliwych jajnika u kobiet. Prz Menopauz. 2011; 2: 95-101.

6. Dharmalingam P, Roopesh Kumar VR, Verma SK. Vascular endothelial growth factor expression and angiogenesis in various grades and subtypes of meningioma. Indian J Pathol Microbiol. 2013; 56(4): 349-354, doi: 10.4103/0377-4929.125286, indexed in Pubmed: 24441220.

7. Reed MJ, Karres N, Eyman D, et al. The effects of aging on tumor growth and angiogenesis are tumor-cell dependent. Int J Cancer. 2007; 120(4): 753-760, doi: 10.1002/ijc.22351, indexed in Pubmed: 17131319.

8. Sadoun E, Reed MJ. Impaired angiogenesis in aging is associated with alterations in vessel density, matrix composition, inflammatory response, and growth factor expression. J Histochem Cytochem. 2003; 51(9): 1119-1130, doi: 10.1177/002215540305100902, indexed in Pubmed: 12923237.

9. Kubo T, Shimose S, Fujimori J, et al. Diversity of angiogenesis among malignant bone tumors. Mol Clin Oncol. 2013; 1(1): 131-136, doi: 10.3892/mco.2012.11, indexed in Pubmed: 24649135.

10. Anders $\mathrm{CK}$, Hsu DS, Broadwater $\mathrm{G}$, et al. Young age at diagnosis correlates with worse prognosis and defines a subset of breast cancers with shared patterns of gene expression. J Clin Oncol. 2008; 26(20): 3324-3330, doi: 10.1200/JCO.2007.14.2471, indexed in Pubmed: 18612148.

11. Colak D, Nofal A, Albakheet A, et al. Age-specific gene expression signatures for breast tumors and cross-species conserved potential cancer progression markers in young women. PLoS One. 2013; 8(5): e63204, doi: 10.1371/journal.pone.0063204, indexed in Pubmed: 23704896.

12. Ito $Y$, Miyauchi $A$, Kihara $M$, et al. Patient age is significantly related to the progression of papillary microcarcinoma of the thyroid under observation. Thyroid. 2014; 24(1): 27-34, doi: 10.1089/thy.2013.0367, indexed in Pubmed: 24001104. 